\title{
Meteorological Predictions for Mars 2020 Perseverance Rover Landing Site at Jezero Crater
}

\author{
Jorge Pla-García ${ }^{1,2}$ (D) - S.C.R. Rafkin³ • G.M. Martinez ${ }^{4,5}$ • Á. Vicente-Retortillo ${ }^{1,5}$. \\ C.E. Newman ${ }^{6}$ H. Savijärvi ${ }^{7,8}$ • M. de la Torre9 ${ }^{9}$ J.A. Rodriguez-Manfredi ${ }^{1}$. \\ F. Gómez ${ }^{1}$ A. Molina ${ }^{1}$ D. Viúdez-Moreiras ${ }^{1}$ - Ari-Matti Harri ${ }^{8}$
}

Received: 18 May 2020 / Accepted: 9 November 2020 / Published online: 14 December 2020

(C) The Author(s) 2020, corrected publication 2021

\begin{abstract}
The Mars Regional Atmospheric Modeling System (MRAMS) and a nested simulation of the Mars Weather Research and Forecasting model (MarsWRF) are used to predict the local meteorological conditions at the Mars 2020 Perseverance rover landing site inside Jezero crater (Mars). These predictions are complemented with the COmplutense and MIchigan MArs Radiative Transfer model (COMIMART) and with the local Single Column Model (SCM) to further refine predictions of radiative forcing and the water cycle respectively. The primary objective is to facilitate interpretation of the meteorological measurements to be obtained by the Mars Environmental Dynamics Analyzer (MEDA) aboard the rover, but also to provide predictions of the meteorological phenomena and seasonal changes that might impact operations, from both a risk perspective and from the perspective of being better prepared to make certain measurements. A full diurnal cycle at four different seasons $\left(\mathrm{L}_{\mathrm{s}} 0^{\circ}, 90^{\circ}, 180^{\circ}\right.$, and $\left.270^{\circ}\right)$ is investigated. Air and ground temperatures, pressure, wind speed and direction, surface radiative fluxes and moisture data are modeled. The good agreement between observations and modeling in prior works [Pla-Garcia et al. in Icarus 280:103-113, 2016; Newman et al. in Icarus 291:203-231, 2017; Vicente-Retortillo et al.
\end{abstract}

The Mars 2020 Mission

Edited by Kenneth A. Farley, Kenneth H. Williford and Kathryn M. Stack

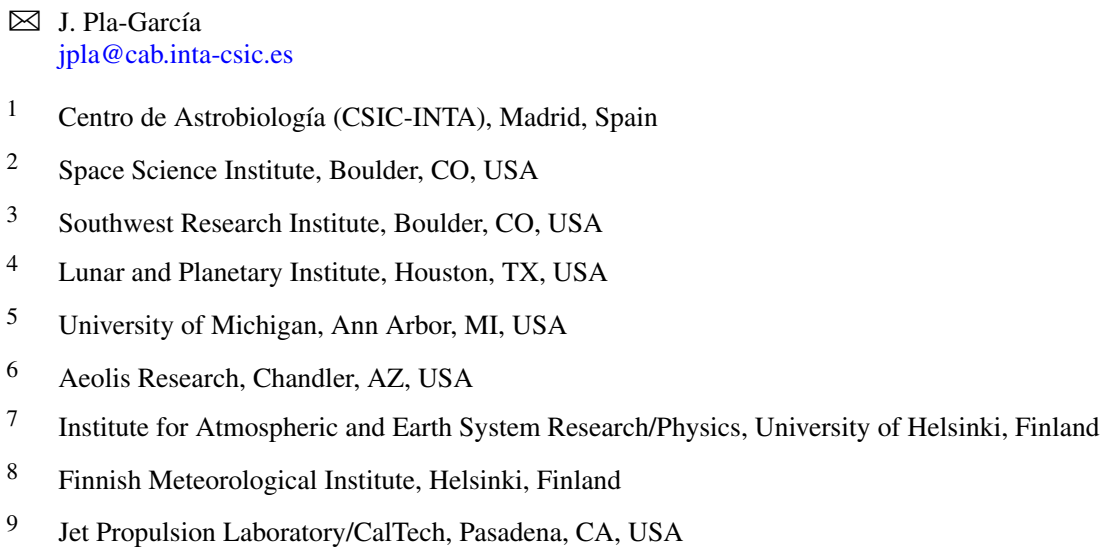


in Sci. Rep. 8(1):1-8, 2018; Savijärvi et al. in Icarus, 2020] provides confidence in utilizing these models results to predict the meteorological environment at Mars 2020 Perseverance rover landing site inside Jezero crater. The data returned by $M E D A$ will determine the extent to which this confidence was justified.

Keywords Mars · Atmosphere $\cdot$ Mars $2020 \cdot$ Perseverance

\section{Highlights}

- Meteorology conditions of the Mars 2020 Perseverance rover landing site are predicted with MRAMS and MarsWRF at four different seasons (solstices and equinoxes).

- Predictions are complemented with the COMIMART radiation and SCM moisture models.

- The results can be compared with future $M E D A$ observations.

\section{Introduction}

The NASA Mars 2020 Perseverance rover will land in Jezero crater, Mars [18.4663 N; 77.4298 E] on February 18, 2021 (Fig. 1). Jezero (which translates to "lake" in Croatian) is a $\sim 45 \mathrm{~km}$ diameter impact crater located in the Nili Fossae region of Mars with fluvio-lacustrine environments dating back to the Noachian-Early Hesperian. This makes it a valuable site to address investigations related to Mars' climate and habitability history, like early Mars atmospheric composition, climate evolution and past water cycles (including rain, snow, and weathering); and search for materials with high potential for biosignature preservation and for potential evidence of past life [Fassett and Head 2005; Schon et al. 2012; Goudge et al. 2015; Horgan et al. 2020; Mandon et al. 2020; Brown et al. 2020]. At the latitude of Jezero crater in the northern hemisphere, both seasonal variability, induced by planetary-scale mean (e.g. Hadley cells) and standing wave features, and daily variability, induced by large-scale baroclinic instability and flushing dust storms, are expected to be large.

The objectives of the Mars 2020 mission are to explore Jezero crater's geological history and potential for habitability, to collect relevant samples for return to Earth, and to make progress on closing strategic knowledge gaps (hereafter SKG) for the human exploration of Mars [Williford et al. 2018]. One of the highest priorities SKG is to validate atmospheric models by taking advantage of the unprecedented set of meteorological quantities that will be measured by this mission [Rodriguez-Manfredi et al. 2020; companion paper in this Special Issue]. This SKG corresponds to objective D2 of the mission [Farley et al. 2020; companion paper in this Special Issue], and this work will help to address it. The meteorological environment provides fundamental constraints relevant for life and habitability, the radiation conditions, soil and air temperature, and water vapor abundance that directly influence habitability.

The Mars Regional Atmospheric Modeling System [Rafkin et al. 2001, 2002; Rafkin 2009; Rafkin and Michaels 2019; hereafter MRAMS] and the Mars Weather Research and Forecasting model [Richardson et al. 2007; Toigo et al. 2012; Newman et al. 2017; Lee et al. 2018; hereafter MarsWRF] have demonstrated the ability to reproduce the observed meteorological conditions on Mars [Ayoub et al. 2014; Pla-Garcia et al. 2016 and Rafkin et al. 2016 (hereafter PGR16); Newman et al. 2017, 2019]. Both of these models are applied here to describe the meteorological conditions at the Mars 2020 Perseverance rover landing site inside Jezero crater for the four cardinal seasons $\left(\mathrm{L}_{\mathrm{s}} 0^{\circ}, 90^{\circ}, 180^{\circ}\right.$, and $\left.270^{\circ}\right)$. The results, 
if the models are reasonably accurate, preview what the Mars Environmental Dynamics Analyzer (MEDA), an integrated full suite of sensors designed to characterize the climate near the Martian surface, will observe. The MEDA sensor suite [Rodriguez-Manfredi et al. 2020; companion paper in this Special Issue] includes a dust and optical radiation sensor (RDS) with a dedicated camera (SkyCam), a pressure sensor $(P S)$, a relative humidity sensor $(H S)$, a wind sensor (WS), five air temperature sensors (ATS), and a thermal infrared sensor for upwelling infrared flux and ground temperature determination (TIRS). As with all meteorological measurements on any planet, accommodation of the sensors is critical. In the case of $M E D A$, all the sensors are located within the thermal and mechanical contamination envelope of the rover, although the Mars 2020 Perseverance rover sensors are better placed to reduce the potential effects of contamination compared to the MSL Curiosity rover [Rodriguez-Manfredi et al. 2020; companion paper in this Special Issue]. This potential for instrument cross-contamination effects will need to be considered when validating the results presented here.

One of the goals of this paper is to present predictions of the meteorology parameters for comparison to observations after Mars 2020 Perseverance rover lands, but also to provide advance predictions of the meteorological phenomena and seasonal changes that might impact operations, from both a risk perspective and from the perspective of being better prepared to make certain measurements. For example, knowing when wind and hence saltation may be strongest, as a function of time of day and season, will be valuable for guiding concept of operations (CONOPS) and deciding when it might be good take measurements, what conditions are expected, and how to better measure that process. It will also be useful for understanding risks to delicate instrumentation, such as cameras placed near the surface. Understanding when water abundances may peak and when the lowest temperatures are expected, may both be useful for planning campaigns linked to cloud observations or surface-atmosphere exchange of water vapor. Another goal is to demonstrate where there is disagreement between models, which motivates in situ measurements of the near-surface atmosphere.

Modest confidence in the models' ability to predict the meteorology is justified because they have been shown to reproduce observations with good fidelity in the limited number of locations where data is available [PGR16; Newman et al. 2017]. However, determining the validity of model predictions has often been hampered by issues with the meteorological datasets, due to e.g. sensor damage [Newman et al. 2017], excessive noise at cold temperatures [Gómez-Elvira et al. 2014], and/or placement of sensors inclose proximity to heat or cold sources [Banfield et al. 2020] or in locations subject to mechanical interference. A more comprehensive analysis of the atmospheric circulation is given in a companion paper in this Special Issue [Newman et al. 2020, hereafter N20].

\section{Numerical Experiments Design and Configuration}

\subsection{Mars Regional Atmospheric Modeling System (MRAMS) Configuration}

A full description of the MRAMS model is included in Rafkin and Michaels (2019) with physics options and initialization similar to PGR16. For this study, MRAMS is configured using seven grids with the innermost grids centered on the Mars 2020 Perseverance rover landing site location inside Jezero crater, Mars [77.4298 $\left.{ }^{\circ} \mathrm{E}, 18.4663{ }^{\circ} \mathrm{N}\right]$ (Fig. 1). The horizontal grid spacing at the center of the seven grids is 240, 80, 26.7, 8.9, 2.96, 0.98 and $0.33 \mathrm{~km}$ respectively. 


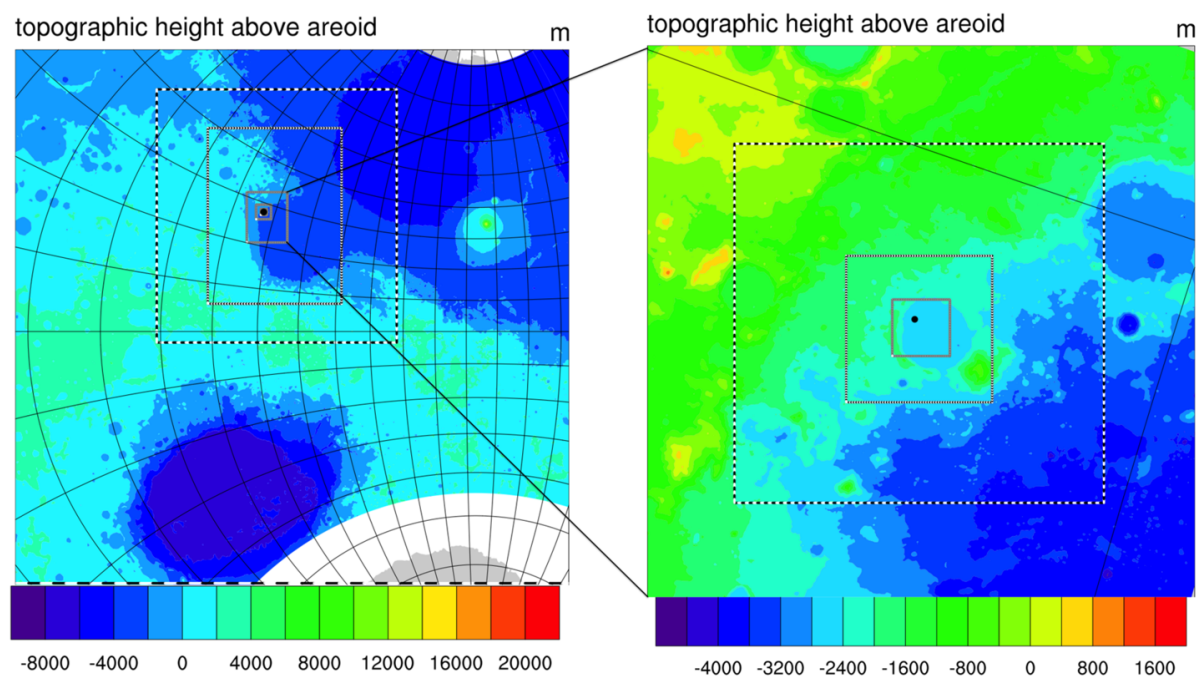

Fig. 1 Horizontal grid spacing for grids 1 to 7 (left) and innermost grids 4 to 7 (right). The grid spacing on each grid is shown by the alternating black and white bars around the border. Topography is shown as color-coded elevation (m) from the Mars Orbiter Laser Altimeter (MOLA)

As shown in Fig. 1, the grids are configured, as much as is practicable, to cover the topographic regions that might influence the solution on a particular grid as described in PGR16. All the grids have the same vertical grid configuration with the vertical winds staggered between thermodynamic levels. This vertical spacing is gradually stretched with height until reaching a maximum spacing of 2,500 $\mathrm{m}$, and the levels gradually transition from terrainfollowing near the surface to horizontal at the top of the model. The spacing does not exceed $100 \mathrm{~m}$ in the lowest $1 \mathrm{~km}$, and does not exceed $400 \mathrm{~m}$ in the lowest $4 \mathrm{~km}$. The model top is at $51 \mathrm{~km}$ with 50 vertical grid points in total. The lowest thermodynamic level, where air temperature and pressure are modeled, is $\sim 14.5 \mathrm{~m}$ above the ground. Ideally, the first vertical level would be located at the $M E D A$ instrument height (with sensors from $\sim 0.5 \mathrm{~m}$ to $\sim 1.5 \mathrm{~m}$ above the ground), but this is not computationally practical, as described in PGR16. $\mathrm{CO}_{2}$ ice is placed on the surface based on the location predicted by the NASA Ames Global Climate Model at the MRAMS initial time. The $\mathrm{CO}_{2}$ ice is static in time during the MRAMS integration, which is justifiable over the short simulation period (sols) and the low latitude location of Jezero crater. The water cycle is not active in these simulations. Table 1 gives values of dust opacity used in MRAMS and MarsWRF as a function of season. Dust is prescribed in MRAMS based on climatological (multiple Mars years), zonally-averaged Thermal Emission Spectrometer (TES) retrievals in non-global dust storm years [Smith et al. 2000]. MRAMS follows Lemmon et al. (2015) method to convert from $9 \mu \mathrm{m}$ to $880 \mathrm{~nm}$ opacity. MarsWRF follows Wolff et al. (2009) method to convert from $670 \mathrm{~nm}$ to $880 \mathrm{~nm}$ opacity.

Table 2 describes the different values used in MRAMS and MarsWRF for horizontal spacing, thermal inertia, albedo and surface roughness at the landing location.

MRAMS model of dust follows a Conrath-v profile in altitude [Conrath 1975]. The Conrath- $v$ parameter that describes the depth of the dust varies with season and latitude. The deepest atmospheric dust column is found near the subsolar latitude.

The model was run for three sols with the first five grids and then the two additional, highest resolution grids were added and run for at least three more sols. The first two sols may be regarded as "spin-up". All simulations were started at or slightly before local sun- 
Table 1 Dust opacity values for MRAMS and MarsWRF

\begin{tabular}{llllc}
\hline $\begin{array}{l}\text { Solar longitude } \\
\text { (mission sol \#) }\end{array}$ & MRAMS 9 $\mu \mathrm{m}$ dust & $\begin{array}{l}\text { MRAMS } \\
880 \mathrm{~nm} \text { dust }\end{array}$ & $\begin{array}{l}\text { MarsWRF } \\
880 \mathrm{~nm} \text { dust }\end{array}$ & $\begin{array}{l}\text { MarsWRF } \\
670 \mathrm{~nm} \text { dust }\end{array}$ \\
\hline $0(658)$ & 0.125 & 0.325 & 0.318 & 0.30 \\
$90(182)$ & 0.086 & 0.223 & 0.201 & 0.19 \\
$180(361)$ & 0.090 & 0.234 & 0.350 & 0.33 \\
$270(501)$ & 0.207 & 0.538 & 0.466 & 0.44 \\
\hline
\end{tabular}

Table 2 Horizontal spacing, albedo, thermal inertia and z0 values for MRAMS and MarsWRF

\begin{tabular}{lllll}
\hline Model & $\begin{array}{l}\text { Horizontal spacing } \\
\text { for comparison }\end{array}$ & Albedo & $\begin{array}{l}\text { Thermal inertia } \\
\left(\mathrm{Jm}^{-2} \mathrm{~K}^{-1} \mathrm{~s}^{-1 / 2}\right)\end{array}$ & $\begin{array}{l}\text { Roughness height, } \\
\mathrm{z} 0(\mathrm{~m})\end{array}$ \\
\hline MRAMS & $0.98 \mathrm{~km}$ & 0.1366 & 259 & 0.030 \\
MarsWRF & $1.4 \mathrm{~km}$ & 0.1342 & 261 & 0.026 \\
\hline
\end{tabular}

rise. MRAMS is not a global model and cannot be run for an entire Mars year. The output frequency that is used for analysis is five Mars minutes with data taken from the grid \#6. In order to obtain representative conditions throughout the Mars year, the model was run for four solar longitudes, corresponding to the particular operational sols for Mars 2020 Perseverance rover, as shown in Table 1.

\subsection{MarsWRF Configuration}

The MarsWRF model is based on the widely-used National Center for Atmospheric Research Weather Research and Forecasting mesoscale model [Skamarock et al. 2008; Powers et al. 2017], but now modified to have a global outer domain and to include parameterizations of Mars physics [Richardson et al. 2007]. This includes treatment of radiative transfer in the Martian atmosphere, including the effects of carbon dioxide gas and ice, aerosol dust, and water vapor and water ice [Mischna et al. 2012; Lee et al. 2018]. The simulations include fully interactive cycles of carbon dioxide. While MarsWRF includes two-moment dust and water ice microphysics, in these simulations the water cycle is not included and dust is prescribed. The simulations include fully interactive cycles of carbon dioxide. The water cycle is not active. The simulations included in this work use the model as configured to simulate Gale crater in Newman et al. [2017, 2019] and are fully described in [N20]. The only differences are the placement of nested domains in the horizontal, with the nests now centered on Jezero crater, and the use of only five domains total. The grid spacing in the global domain (domain 1 ) is $2^{\circ}$, with the resolution increasing by a factor of 3 in each subsequent domain. Grid \#5 has grid spacing of $\sim 1.4 \mathrm{~km}$. Topography in MarsWRF global domain and nests is shown in Fig. 1 of [N20].

The model's radiative transfer, planetary boundary layer, surface, subsurface schemes, and surface properties are all identical to Newman et al. [2017, 2019]. Vertical grid A shown in Table 2 of Newman et al. (2017) is used in this work and consists of 43 layers covering the surface to $\sim 80 \mathrm{~km}$ three layers with greater vertical resolution in the boundary layer (below $\sim 12 \mathrm{~km}$ typically on Mars); three layers have their midpoint below $150 \mathrm{~m}$, with the lowest layer midpoint at $\sim 10 \mathrm{~m}$ above the surface. The time-varying 3-D dust distribution 
Table 3 MRAMS pressure adjustment

\begin{tabular}{llll}
\hline Season (Ls) & MRAMS mean pressure & MarsWRF mean pressure & $f p$ \\
\hline 0 & 726.0 & 722.0 & 0.994 \\
90 & 764.1 & 715.7 & 0.936 \\
180 & 652.2 & 653.7 & 1.002 \\
270 & 794.7 & 804.9 & 1.012 \\
\hline
\end{tabular}

Table 4 Diurnal pressure amplitude variation from the mean from MRAMS and MarsWRF as a function of season

\begin{tabular}{lll}
\hline Solar longitude (mission sol \#) & $\begin{array}{l}\text { MRAMS diurnal pressure } \\
\text { amplitude variation from the mean }\end{array}$ & $\begin{array}{l}\text { MarsWRF diurnal pressure } \\
\text { amplitude variation from the mean }\end{array}$ \\
\hline $0(658)$ & $2.4 \%$ & $2.2 \%$ \\
$90(182)$ & $1.5 \%$ & $1.0 \%$ \\
$180(361)$ & $3.2 \%$ & $2.4 \%$ \\
$270(501)$ & $2.7 \%$ & $2.6 \%$ \\
\hline
\end{tabular}

is prescribed in these MarsWRF simulations to match TES limb and nadir opacities observations at $2 \mathrm{pm}$ and 2 am in years without global dust storms, with observations interpolated sinusoidally in time, as in Guzewich et al. (2013).

\section{Mesoscale Modeling Results}

For comparison with the innermost grid of MarsWRF (spatial resolution of $\sim 1.4 \mathrm{~km}$ between points in the horizontal), we chose to use the data from grid \#6 of MRAMS (spatial resolution of $\sim 0.98 \mathrm{~km}$ between points in the horizontal) because this is more comparable to the innermost grid spacing in MarsWRF. The information on the grid \#6 of MRAMS is averaged from grid \#7. MarsWRF outputs onto a slightly different vertical grid with its lowest layer midpoint at $10 \mathrm{~m}$, but these results are extrapolated from $1.5 \mathrm{~m}$ level up to $14.5 \mathrm{~m}$ to be directly comparable with the first (lowest) thermodynamic layer of MRAMS.

\subsection{Pressure}

A comparison of MRAMS and MarsWRF pressures is shown in Fig. 2. The diurnal perturbations about the daily mean pressure result from the thermal tide (dominated by the diurnal and semidiurnal modes) and by regional and local circulations. The global signal is provided by the global domain of the nested MarsWRF simulation, whereas MRAMS cannot simulate the global $\mathrm{CO}_{2}$ cycle and instead inherits global information the NASA Ames General Circulation Model [Kahre et al. 2006] through initial conditions and time-varying boundary conditions of grid 1 . The mean daily pressure at a given season is controlled by the global $\mathrm{CO}_{2}$ budget. Because each model has slightly different global $\mathrm{CO}_{2}$ cycles, the mean diurnal pressures do not completely agree. The MRAMS pressure results shown in Fig. 2 were adjusted to fit with the daily mean pressure from MarsWRF shown in Table 3.

To better identify any difference in structure predicted by the models, the diurnal pressure amplitude as a function of season is shown in Table 4. 

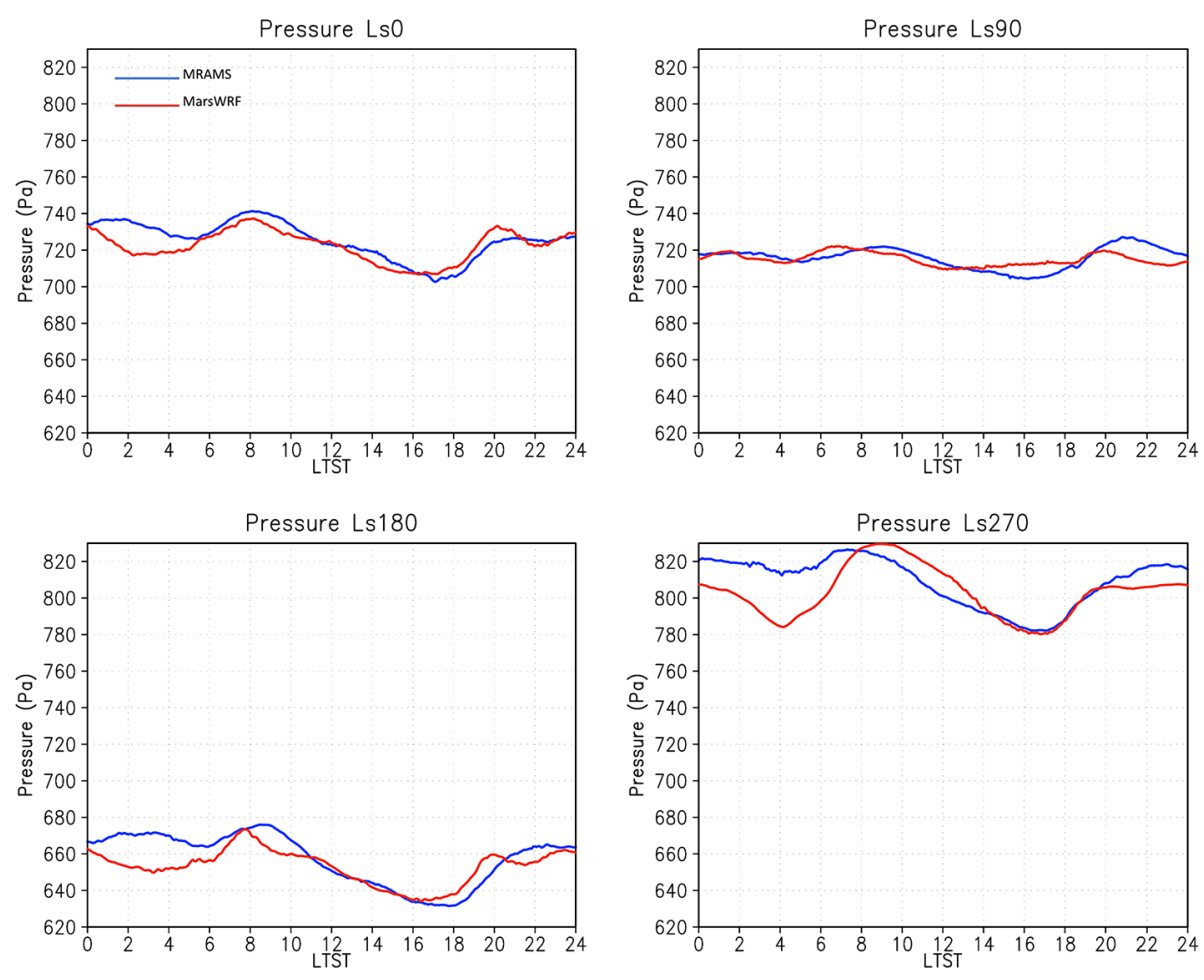

Fig. 2 Modeled diurnal pressure signal as function of season for Jezero crater using MRAMS (blue curve) and MarsWRF (red curve)

The diurnal amplitude varies from $1 \%$ to $3.2 \%$ depending on the season and model. The total amplitude is then considerably smaller compared to Gale crater (up to $\sim 13 \%$, PGR16). PGR16 and Tyler and Barnes (2013) found that the circulation at Gale crater generally phased with the thermal tide to amplify the amplitude of the diurnal pressure signal at Gale crater. Richardson and Newman (2018) attributed the amplification to a mesoscale hydrostatic adjustment process in regions of topographic slopes.

Both models also show similar phasing of the most dominant modes although they are not identical. Differences of one to two hours are evident (e.g., the maximum and minimum pressures at $\mathrm{L}_{\mathrm{s}} 90^{\circ}$ and $\mathrm{L}_{\mathrm{s}} 180^{\circ}$ and maximum pressure at $\mathrm{L}_{\mathrm{s}} 270^{\circ}$ ). There are also places where the models show different higher frequency structure, for example MRAMS shows a local pressure maximum at $\sim$ 02:00 LTST at $\mathrm{L}_{\mathrm{s}} 0^{\circ}$ and $\mathrm{L}_{\mathrm{s}} 180^{\circ}$ while MarsWRF shows a local minimum. N20 describes the underlying dynamics and thermodynamics that are driving some of the differences described here.

\subsection{Ground Temperature Predictions}

$M R A M S$ vs MarsWRF ground temperature comparisons are shown in Fig. 3. Ground temperature is a diagnostic of the energy balance of the surface with contributions from insolation, solar reflection, downward (atmospheric) infrared flux, upward longwave radiative flux from the surface, subsurface conduction, turbulent (atmospheric) heat flux (also called sensible heat flux), and latent heating from phase change of atmospheric gases. There is no latent heating at the location of Jezero crater in either model. 

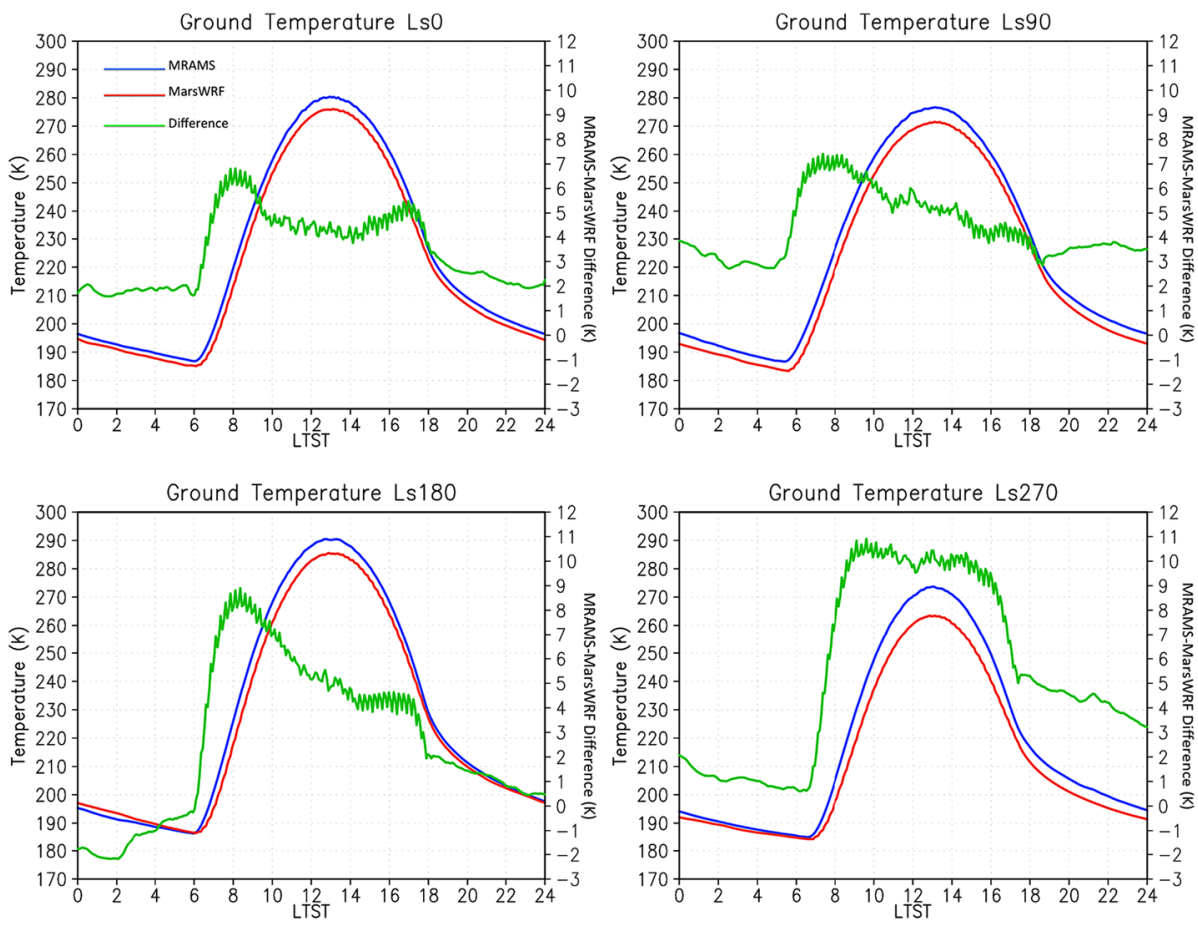

Fig. 3 Same as Fig. 2, but for ground temperature and including MRAMS-MarsWRF temperatures differences (green line)

The general shape of the diurnal cycle of surface temperature are similar between the two simulations, but this is expected given that they are strongly controlled by the time variation of solar insolation. Looking more closely, there are some significant differences between the model predictions. Some of the slightly warmer temperatures at night and $\sim 5 \mathrm{~K}$ warmer temperatures during the day in MRAMS compared with MarsWRF during all seasons could be attributed to a combination of differences in the radiative transfer and subsurface schemes used in the models and differences in specified values of dust loading, albedo and thermal inertia (Tables 1 and 2) [Kieffer 2013; Vasavada et al. 2012]. It could also be due to differences in parameterized turbulence and heat fluxes. Also, while MRAMS uses a dust prescription from zonally-averaged TES daily maps, MarsWRF is using longitudinally-varying $T E S$-derived dust maps with a time-of-day variation resulting from sinusoidally interpolating between 2 am and 2 pm values. So, we should expect differences in the tides anyhow that would affect temperatures. MRAMS thermal inertia is slightly lower compared to MarsWRF (Table 2), so the diurnal ground temperature curves in MRAMS are likely to overestimate the diurnal amplitude with warmer temperatures during the day but cooler at night. This may reconcile MRAMS with MarsWRF daytime temperatures but has the opposite effect at night. Also, insolation and the downward infrared flux are affected by the atmospheric dust loading. Generally, dust has an anti-greenhouse effect at solar wavelengths, but acts as a greenhouse in the infrared [PGR16; Clancy et al. 1995]. Thus, an increase in dust loading reduces the solar input at the surface and increases the downwelling infrared radiation. The net result is an increase of the nighttime temperatures and decrease in daytime. Because MarsWRF dust opacity values are lower than those for $M R A M S$ at $\mathrm{L}_{\mathrm{s}} 0^{\circ}, \mathrm{L}_{\mathrm{s}} 90^{\circ}$ and $\mathrm{L}_{\mathrm{s}} 270^{\circ}$ 

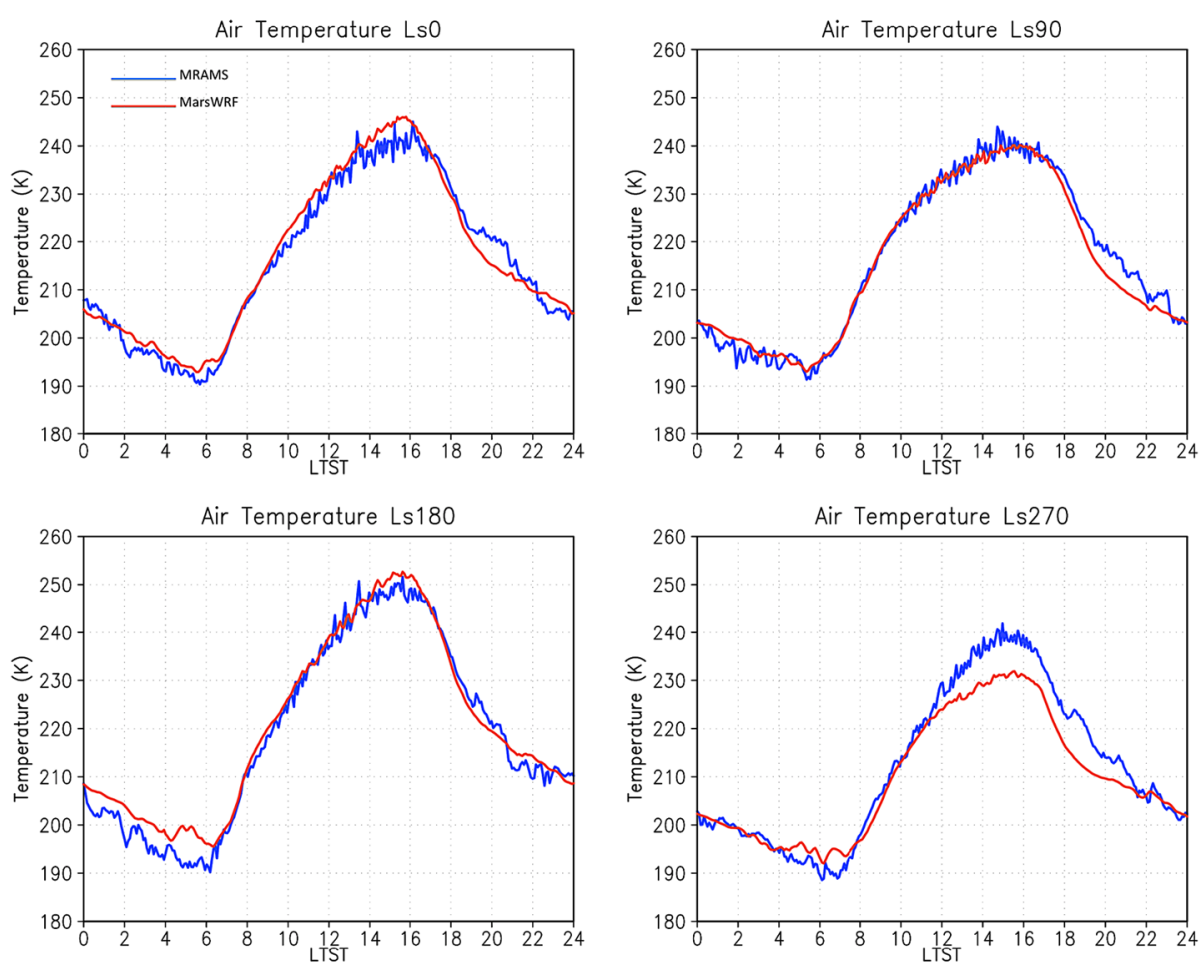

Fig. 4 Same as Fig. 2, but for air temperature. Both MRAMS and MarsWRF data is from the lowest atmospheric layer centered at $\sim 14.5 \mathrm{~m}$

as shown in Table 1, that may help to reconcile MRAMS and MarsWRF nighttime temperatures, but does the opposite during the day. During $\mathrm{L}_{\mathrm{s}} 180^{\circ}$, Mars $W R F$ dust opacity values are bigger than those for MRAMS, may helping to reconcile MRAMS and MarsWRF dayttime temperatures, but does the opposite during the night. The differences in dust vertical prescription and assumed dust properties are likely the largest control on these results, in additional to the surface thermal properties, but it is hard to trace the cause back to one aspect specifically. In future, we plan to perform new simulations using the same dust prescription and properties in both models to assess this further.

\subsection{Air Temperatures Predictions}

$M R A M S$ vs MarsWRF air temperatures comparisons are shown in Fig. 4.

From the start, it must be noted that, because of the different accommodations of MEDA air temperature sensors (ATS), observations will be taken at $\sim 0.5 \mathrm{~m}$ and $\sim 1.5 \mathrm{~m}$ above ground level [Rodriguez-Manfredi et al. 2020; companion paper in this Special Issue], while MRAMS provides air temperature for the atmospheric model layer centered at $\sim 14.5 \mathrm{~m}$ and MarsWRF output has also been interpolated to this level. Based on the known thermal structure of the martian atmosphere (unstable during the day, stable at night; [Schofield et al. 1997]), both MRAMS and MarsWRF values at this height should tend to be cooler during the day and warmer during the night compared to the air at $\sim 0.5 \mathrm{~m}$ and $\sim 1.5 \mathrm{~m}$ [PGR16]. A clear afternoon bias, with $M R A M S \sim 10 \mathrm{~K}$ warmer than MarsWRF is found at $\mathrm{L}_{\mathrm{s}} 270^{\circ}$. This is to be expected as MRAMS also has daytime peak surface temperatures $\sim 10 \mathrm{~K}$ higher 
than in MarsWRF in this season, and surface temperature strongly controls near-surface air temperature via radiative heating, convection, and conduction. No obvious bias is found at other times or at other seasons.

The warmest period (of those considered), with air temperatures of $\sim 251 \mathrm{~K}$, is found to be around $\mathrm{L}_{\mathrm{s}} 180^{\circ}$ in both models. MRAMS shows a high temperature of $\sim 242 \mathrm{~K}$ at all other seasons, while MarsWRF has a peak temperature of $\sim 245 \mathrm{~K}$ at $\mathrm{L}_{\mathrm{s}} 0^{\circ}, \sim 240 \mathrm{~K}$ at $\mathrm{L}_{\mathrm{s}} 90^{\circ}$, and $\sim 232 \mathrm{~K}$ at $\mathrm{L}_{\mathrm{s}} 270^{\circ}$ (the smallest maximum temperature of all the results). The overall shape of the diurnal curve clearly changes as a function of season, but both models respond to the seasonal change and show very similar patterns.

The most striking difference between the models is the larger amplitude and usually higher-frequency variations in MRAMS air temperatures compared to those in MarsWRF. The variations seen in MRAMS are similar to those modeled in Gale crater and generally match the observed high frequency variations [PGR16]. During the day, the variations can be attributed to resolved convective motions. The atmosphere is not convective at night, so the variations must be due to mechanical mechanisms that force warm air to descend or cold air to rise. These mechanisms could be the interaction of the wind with the topography or strong shear (e.g., a nocturnal low-level jet) at the nocturnal inversion interface. Smoother curves were also predicted for Gale crater by MarsWRF [Newman et al. 2017] compared to predictions by MRAMS [PGR16]. This could partly be due to the higher resolution used in $M R A M S$, but may also be suggestive of more diffusion in MarsWRF. A similar difference, also attributed to differences in diffusion, were noted in the comparison of the $L M D$ version of MarsWRF to MRAMS [Bertrand et al. 2014]. However, it should also be noted that there are dynamical concerns associated with running MRAMS and MarsWRF at such high horizontal resolutions (and MRAMS at a higher resolution than MarsWRF), such that some but not all eddies are resolved. As this occurs, the models move into the "terra incognita" or "gray zone" [Wyngaard 2004; Newman et al. 2017] in which they begin "double counting" eddy effects (as both still include parameterizations of mixing by unresolved eddies, which are assumed to be all of them by the parameterization schemes). The models also begin to allocate eddy energy into the smallest scales that can be resolved, rather than producing the correct distribution of scales (as would be possible in a Large Eddy Simulation going down to $\sim$ meter scales). This likely influences results, although the degree to which it may adversely affect predictions remains unclear for Mars, due to the lack of boundary layer measurements available to date.

\subsection{Wind Speed and Direction Predictions}

The wind speed and wind direction comparisons $M R A M S$ vs MarsWRF are shown in Figs. 5 and 6 , respectively.

Wind speeds at $\mathrm{L}_{\mathrm{s}} 270^{\circ}$ are lower than those observed and modeled at MSL Curiosity rover locations in this season [PGR16; Viúdez-Moreiras et al. 2019a, 2019b, Newman et al. 2017]. Unlike Gale crater, which has a pronounced windy season at $L_{s} 270^{\circ}$, Jezero crater is modestly windy all year. The strongest winds occur in the mid-afternoon (when upslope winds are strongest), peaking at $\sim 16 \mathrm{~m} / \mathrm{s}$ at $\mathrm{L}_{\mathrm{s}} 0^{\circ}$ and $\mathrm{L}_{\mathrm{s}} 180^{\circ}$ (equinoxes) in both models. The weakest winds $(\sim 2 \mathrm{~m} / \mathrm{s})$ occur right before sunset (in the short period when the planetary boundary layer collapses) and late at night for all seasons in both models.

During all seasons, the modeled winds have a $\sim \mathrm{NW}\left(\sim 315^{\circ}\right)$ component during the night and then transition to a $\sim \mathrm{SE}\left(\sim 135^{\circ}\right)$ direction during the day (Fig. 6). This behavior is consistent with winds on the NW slope of Isidis Basin, with an atmospheric circulation dominated by the regional scale over the local and global scale. During the day, due to the 

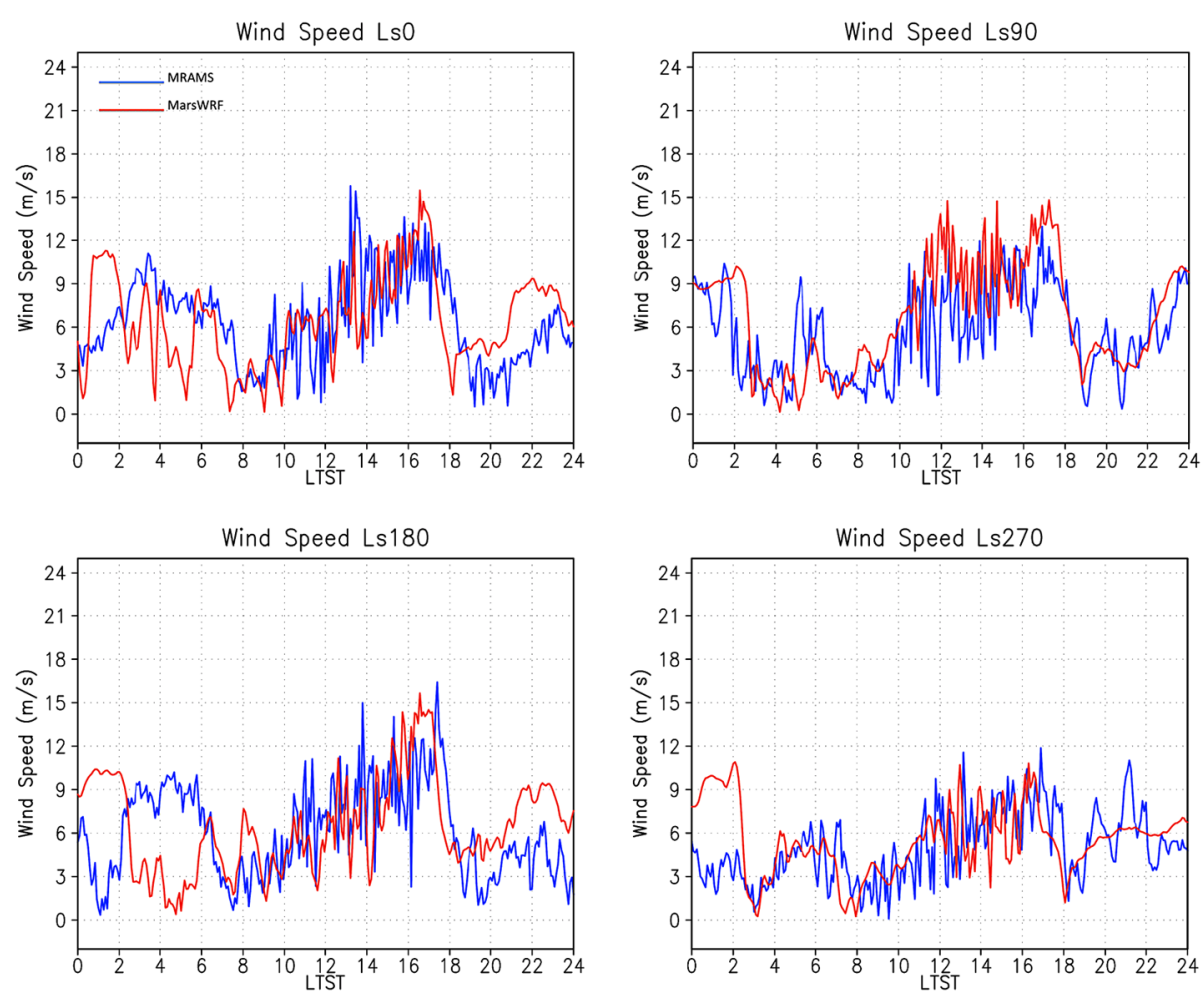

Fig. 5 Same as Fig. 2, but for wind speed

upward slope, winds rise toward the edges of Isidis basin and at night the process reverses. The reader should proceed no further without first viewing the animations of those circulations provided in the Supplementary Material. In conclusion, the local winds at Jezero crater are strongly controlled by the regional Isidis basin topography. [N20] discusses in greater detail the circulations driving the daily cycle.

A striking similarity is that both models tend to show a lot of variability in wind speed during the convective periods in the middle of the day, when both show high-frequency variations in air temperature also. This is likely due to strong daytime convective turbulence (see animations in Supplementary Material). There is also considerable variability in wind direction, although this is reduced at $\mathrm{L}_{\mathrm{s}} 90^{\circ}$ because of positive reinforcement between the global Hadley circulation and regional slope winds that strongly dictate the daytime wind direction at this time of year [Supplementary Material and N20]. Note that at night and in the early morning, MRAMS has significantly more variability in wind speed than MarsWRF, which is consistent with the increased air temperature variability at this time of sol in MRAMS compared to MarsWRF (Fig. 4), and is likely also a result of the stronger diffusion (either explicit or implicit) in MarsWRF.

\subsection{Turbulence Kinetic Energy Predictions}

The effect of subgrid-scale eddies is captured within $M R A M S$ via a prognostic turbulent kinetic energy (hereafter TKE, Fig. 7) equation [Mellor and Yamada 1974]. MarsWRF uses a lower order turbulent closure and TKE information is not available from that model. 

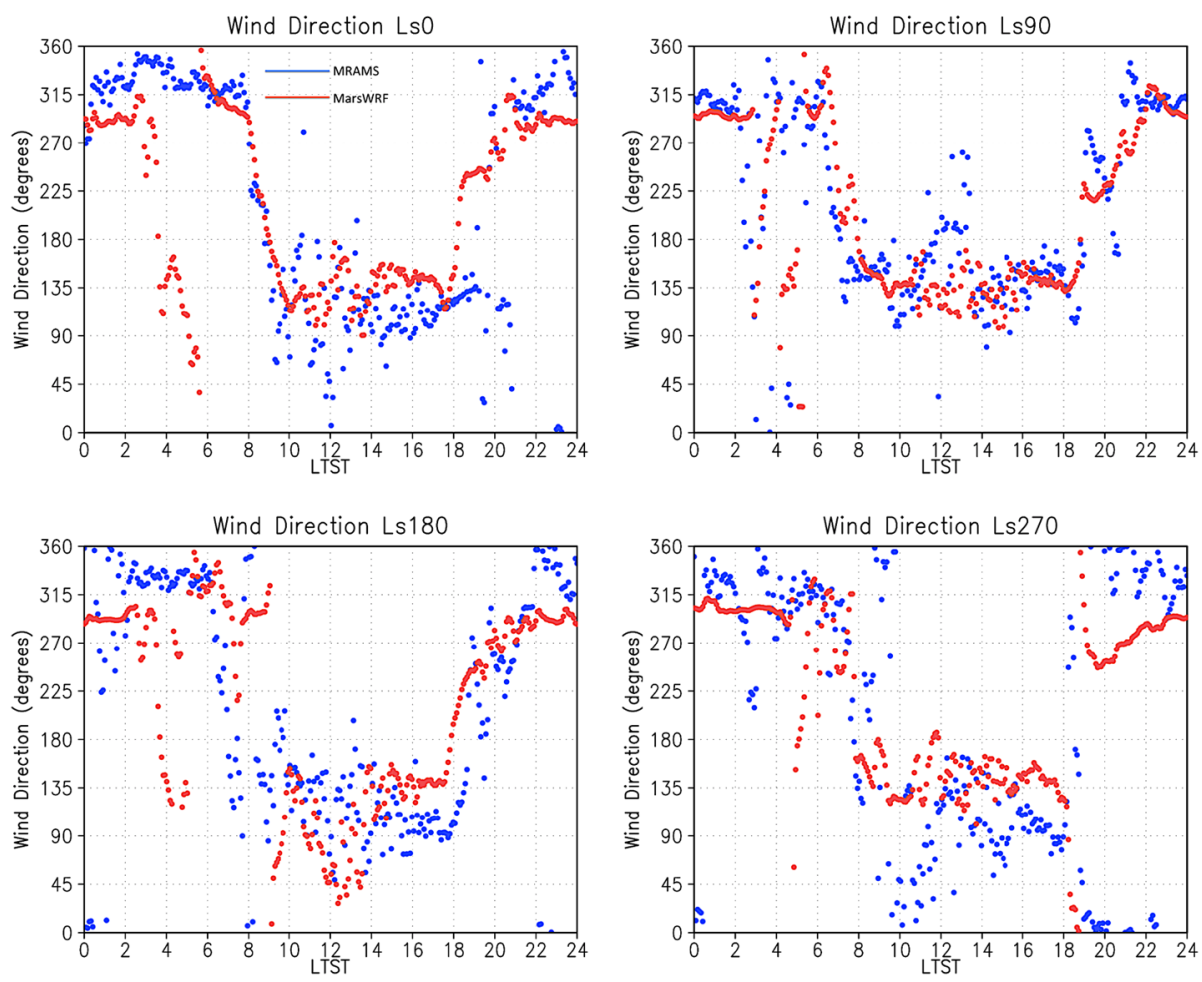

Fig. 6 Same as Fig. 2, but for wind direction. Direction is given as standard meteorological convention with $0 / 360$ being wind from the north

Fig. 7 Turbulent Kinetic Energy predicted with MRAMS for Jezero crater. Hours in LTST

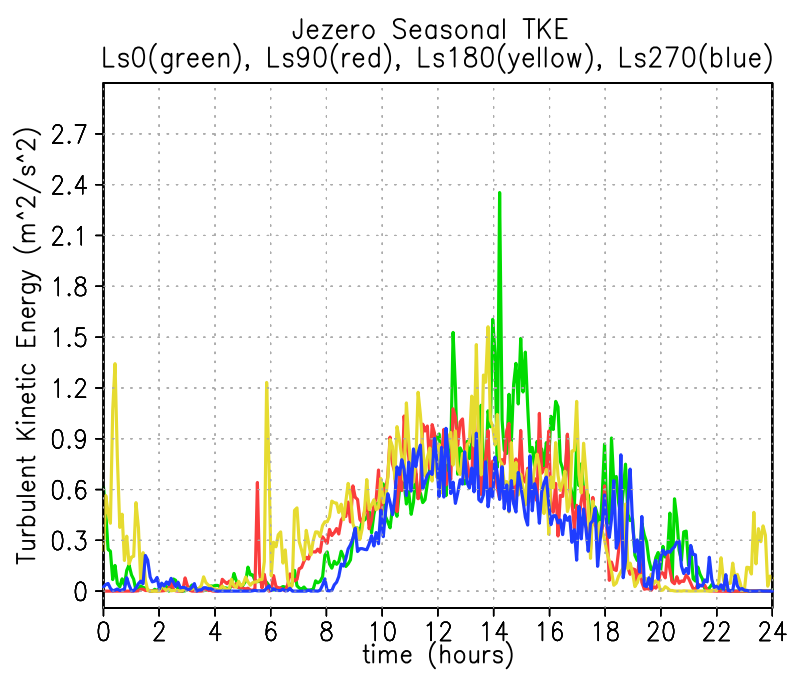

MRAMS shows a peak in TKE during the afternoon, which is consistent with the observed high-frequency variations in air temperatures (Fig. 4). The sudden increase in air temperature during the evenings (Fig. 4) at the onset of radiative cooling is produced by 
mechanically driven turbulence since the atmosphere is stable and non convective in the evening. The model does often show small increases of TKE during the night (Fig. 7), especially during $L_{s} 180^{\circ}$, that could be associated with the turbulent aspects of the nighttime dynamical flows when compared with nearby locations with more flat topography [N20]. During the late evening and night, MRAMS is resolving thermal variations (Fig. 4) and does often show small increases of turbulent kinetic energy at that time (Fig. 7). The rapid air temperature fluctuations observed at night in all seasons for both models is indicative of nocturnal turbulence. The origin of this nocturnal turbulence is explored in animations (Suplementary Material) of vertical slices from east to west of Jezero crater during a whole sol as a function of season, including wind in the plane of the animation (vectors), horizontal wind speed in the plane of the animation (shaded) and potential temperature (contours) from grid \#6. There is no evidence of significant wave activity during the whole period studied and no gravity waves were found. The nighttime turbulence could be attributed to shear driven turbulence and may be explained due to an enhanced mechanical turbulence driven by increasingly strong shear (onset of the nocturnal low-level jet) at the nocturnal inversion interface. As the nocturnal inversion develops, the winds above become decoupled from the surface and the decrease in friction produces a net acceleration [Davis 2000; Blackadar 1957; Thorpe and Guymer 1977; Mahrt 1981]. Once the critical Richardson Number is reached $(\mathrm{Ri} \sim<0.25)$, shear instabilities can mix warmer air aloft down to the surface [Miles 1961; Banfield et al. 2020].

\subsection{Radiation Predictions}

Both MRAMS and MarsWRF use two stream radiative codes with a limited number of spectral bands, which makes it difficult to compare directly with the spectral radiance bands on MEDA. COMIMART [Vicente-Retortillo et al. 2015] simulates spectral irradiances at any wavelength of the shortwave range. Here we perform the simulations in five different solar bands: 250-400, 410-490, 625-675, 190-1000 and 190-3000 nm. The first four bands correspond to the channels 3, 4, 5 and 7 of the channels that point to the zenith of the Radiation and Dust Sensor-RDS- [Rodriguez-Manfredi et al. 2020; companion paper in this Special Issue]. The fifth band, although not associated with any $R D S$ channel, corresponds to the entire shortwave range, which is a key term of the surface energy budget. The model includes wavelength-dependent radiative properties of suspended dust, obtained from the refractive indices derived from CRISM and MARCI observations [Wolff et al. 2009, 2010]. Dust radiative properties have been computed using a T-matrix code [Mishchenko and Travis 1998] assuming that particles are cylinders with a diameter-to-length ratio of 1 [Wolff et al. 2009]. After being fed with the dust opacities that are used in MRAMS, COMIMART computes the solar fluxes using the delta-Eddington approximation [Joseph et al. 1976]. The accuracy of these fluxes has been validated using DISORT [Stamnes et al. 1988; Vicente-Retortillo et al. 2015].

COMIMART results over the five different bands and at six solar longitudes are shown in Fig. 8. The lowest values are found at $\mathrm{L}_{\mathrm{s}} 270^{\circ}$ due to the high atmospheric dust loading during the northern hemisphere winter solstice. MRAMS and MarsWRF predict radiative forcing that drives the highest temperatures at $\mathrm{L}_{\mathrm{s}} 180^{\circ}$ (Figs. 3 and 4), in agreement with $C O M$ MIMART results (Fig. 8). Relative annual variations are larger at shorter wavelengths (250$400 \mathrm{~nm}$ ) because dust absorbs a larger fraction of the incoming radiation in the ultraviolet than in the visible and near infrared regions of the spectrum [Wolff et al. 2010; Brown 2014]. 

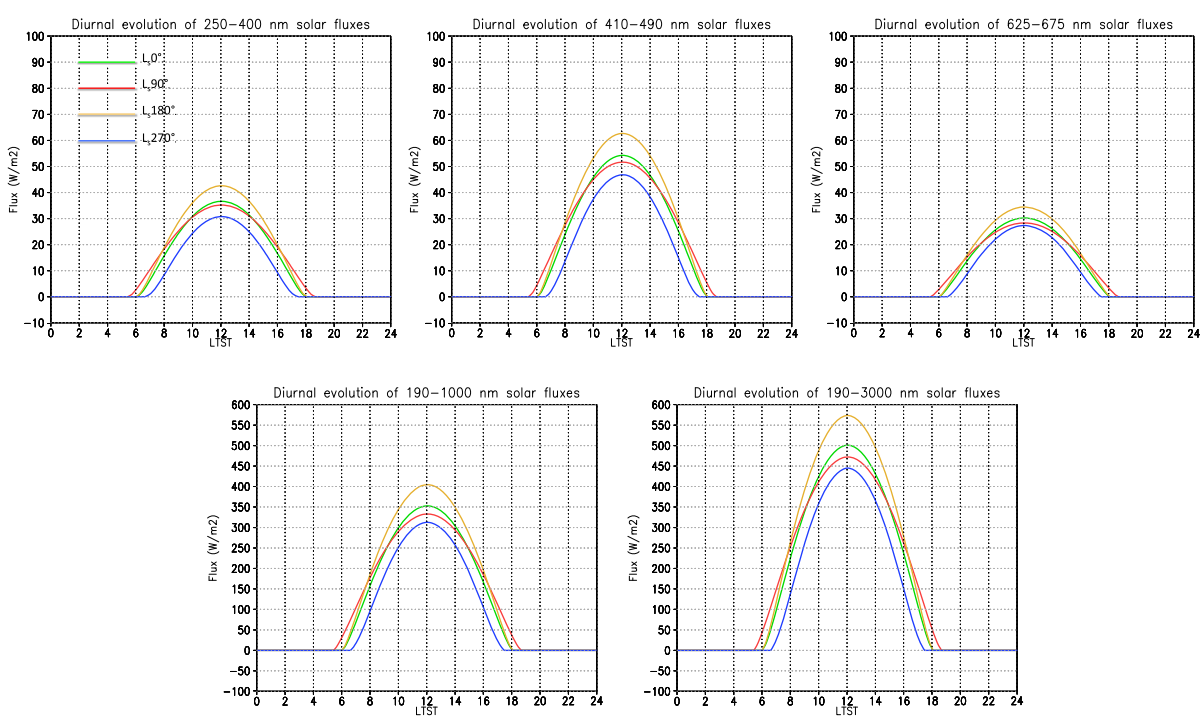

Fig. 8 Diurnal radiation evolution of 250-400, 410-490, 625-675, 190-1000 and 190-3000 nm solar fluxes simulated with COMIMART for Jezero crater

Fig. 9 Near-surface hourly water vapor volume mixing ratios from Phoenix TECP, sols 50-60 (obs) from Fischer et al. (2019), and from the UH/FMI single column model simulation (SCM). PWC is here about $30 \mu \mathrm{m}$ (midsummer at $68^{\circ} \mathrm{N}$ ), just after the sublimation of the north pole water ice cap

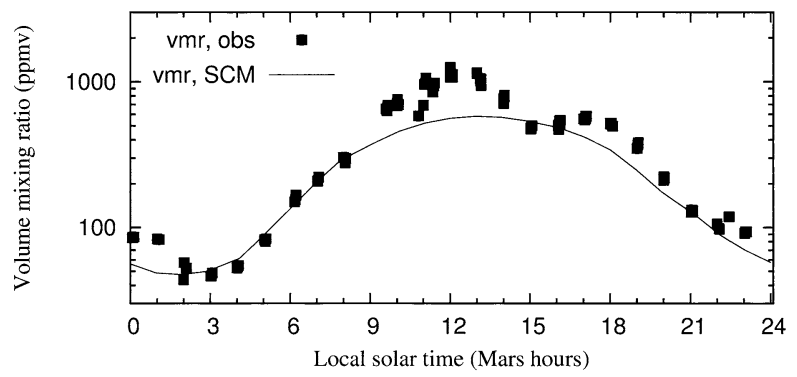

\subsection{Moisture Prediction}

Neither MRAMS nor MarsWRF have their water cycle active in these simulations. Thus, predictions of the near-surface water cycle are made using the local Single Column Model (the University of Helsinki/Finnish Meteorological Institute, hereafter SCM), assuming a typical regolith-covered environment and normal dustiness [Savijärvi and Määttänen 2010; Savijärvi et al. 2016, 2017, 2020]. The diurnal adsorption/desorption of water at the top of the regolith is included in the SCM model as described in Savijärvi et al. (2020) and validated via Phoenix observations in Fig. 9.

\subsubsection{SCM Experiment Design}

In the Jezero site experiments for $18.4^{\circ} \mathrm{N}, 77.4^{\circ} \mathrm{E}$, the soil is assumed regolith-covered with a porosity of $35 \%$, thermal inertia of $\sim 300$ SI units and surface albedo of $\sim 0.20$, based on the respective mappings of the crater area from orbit. These values may be compared with Table 2. There are 29 points at heights of $0.3,0.7,1.6,3.7,8.5,20 \mathrm{~m}, \ldots, 50 \mathrm{~km}$ from the surface. The top is at $50 \mathrm{~km}$. The model is initialized with a $10 \mathrm{~m} / \mathrm{s}$ geostrophic wind and 
Table 5 SCM input values: Local surface pressure p (Pa), dust visible optical thickness $\tau$, high cloud precipitable ice content PIC $\left(\mathrm{g} / \mathrm{m}^{2}\right)$ and precipitable water content PWC $(\mu \mathrm{m})$ from MCD v5.3 for $18.4^{\circ} \mathrm{N}, 77.6^{\circ} \mathrm{E}$ (Jezero site), at 1200 local time. The last line (TES, $\mu \mathrm{m})$ is the MY26 zonal mean PWC for $18^{\circ} \mathrm{N}$ normalized to $610 \mathrm{~Pa}$ from MGS/TES (Montmessin et al. 2017, Fig. 11.3)

\begin{tabular}{lllllllllllll}
\hline $\mathrm{L}_{\mathrm{s}}$ & $0^{\circ}$ & $30^{\circ}$ & $60^{\circ}$ & $90^{\circ}$ & $120^{\circ}$ & $150^{\circ}$ & $180^{\circ}$ & $210^{\circ}$ & $240^{\circ}$ & $270^{\circ}$ & $300^{\circ}$ & $330^{\circ}$ \\
\hline $\mathrm{p}$ & 731 & 753 & 762 & 716 & 650 & 624 & 648 & 710 & 788 & 798 & 754 & 731 \\
$\tau$ & 0.57 & 0.38 & 0.32 & 0.30 & 0.32 & 0.38 & 0.48 & 0.73 & 0.98 & 0.84 & 0.70 & 0.71 \\
$\mathrm{PIC}$ & 0.05 & 0.08 & 0.44 & 0.98 & 0.91 & 0.32 & 0.04 & 0.04 & 0.06 & 0.06 & 0.06 & 0.05 \\
$\mathrm{PWC}$ & 11.3 & 11.7 & 14.6 & 21.2 & 24.9 & 22.7 & 17.3 & 12.3 & 11.5 & 11.8 & 11.0 & 10.5 \\
$\mathrm{TES}$ & 11 & 10 & 9.5 & 10 & 17 & 19 & 16 & 14 & 11 & 12 & 13 & 9.5 \\
\hline
\end{tabular}

roughness height $z 0=0.01 \mathrm{~m}$; this produces $1.6 \mathrm{~m}$ wind speeds of about $4 \mathrm{~m} / \mathrm{s}$ at night and $6 \mathrm{~m} / \mathrm{s}$ during the day, as generally found near the surface by the previous landers [Martínez et al. 2017].

The Jezero experiments are made for a normal-dustiness martian year in increments of $\mathrm{L}_{\mathrm{s}} 30^{\circ}$, taking for each $\mathrm{L}_{\mathrm{S}}$ the site surface pressure, the dust visible optical depth $\tau$ (assumed to be vertically well-mixed) and the precipitable ice content (hereafter PIC) from the GCMbased Mars Climate Database (MCD v5.3, Millour et al. 2018) at midday, 1200 local time (LT), $12 \mathrm{~h}$ (Table 5). Assuming an effective radius (er) of $10 \mu \mathrm{m}$, ice cloud visible optical depth (hereafter $\tau \mathrm{i}$ ) is estimated using the large particle approximation, $\tau \mathrm{i}=1.5 \mathrm{PIC} / \mathrm{er}$. The moisture aspects in MCD v5.3 are from Navarro et al. (2014); the diurnal adsorption mechanism was, however, not included. Hence the MCD near-surface moisture values are the most representative during local midday, when all the nocturnal adsorbed moisture has been returned to the atmosphere.

For each $\mathrm{L}_{\mathrm{s}}$ the SCM is initialized from surface temperature of $220 \mathrm{~K}$ with a lapse rate of $1 \mathrm{~K} / \mathrm{km}$, and is then run for three sols, keeping $\mathrm{p}, \tau$ and $\tau \mathrm{i}$ constant. Initialization of moisture from a given column precipitable water content (hereafter PWC) is discussed below. Results are shown from sol 3, at which point the model has a repeatable diurnal cycle.

\subsubsection{SCM Model Moisture Results}

Figure 10 shows the input data for the column water content. The solid line displays the orbit-observed zonal mean PWC for the Jezero latitude $\left(18^{\circ} \mathrm{N}\right)$ from MGS/TES during Mars Year 26, scaled from the nominal $610 \mathrm{~Pa}$ to the site surface pressure. MY26 was chosen because it best represents the normal-dustiness Mars year in the mesoscale model simulations of Steele et al. (2017) for the Gale crater. Steele et al. furthermore displayed maps of TES PWC for three MY26 periods, Ls $60^{\circ}-80^{\circ}, 180^{\circ}-200^{\circ}$ and $310^{\circ}-330^{\circ}$, from which the observed local TES PWC over Jezero can be assessed.

Figure 10 also shows the zonal mean PWC for $18^{\circ} \mathrm{N}$ and the local PWC at the Jezero site from $M C D$. The northern hemisphere summer water pulse appears to reach the Jezero latitude sooner and is stronger in MCD than in the TES MY26 data, whereas the dry perihelionnorthern winter season appears drier in the $M C D$ data. We use the variability of Fig. 10 to our advantage by initializing the $S C M$ at each Ls using the two column water extremes of Fig. 10: the local $M C D$ PWC and the TES zonal mean MY26 PWC for $18^{\circ} \mathrm{N}$. The difference in the results then bounds the solution given the uncertainty in the local moisture conditions. Table 5 provides the $S C M$ input values which we used.

The Jezero region, at $18^{\circ} \mathrm{N}$, is within the large-scale meridional Hadley cell such that the horizontal lower equatorial branch of the Hadley circulation transports near surface dry 
Fig. 10 The MGS/TES MY26 zonal mean PWC values for $18^{\circ} \mathrm{N}$ scaled to the Jezero surface pressure (TES zm), the $M C D$ $12 \mathrm{~h}$ zonal mean PWC values for $18^{\circ} \mathrm{N}(M C D \mathrm{zm})$, and the $M C D$ $12 \mathrm{~h}$ local $\mathrm{PWC}$ values at the Jezero point $\left(18.4{ }^{\circ} \mathrm{N}, 77.6^{\circ} \mathrm{E}\right)$ (MCD local)
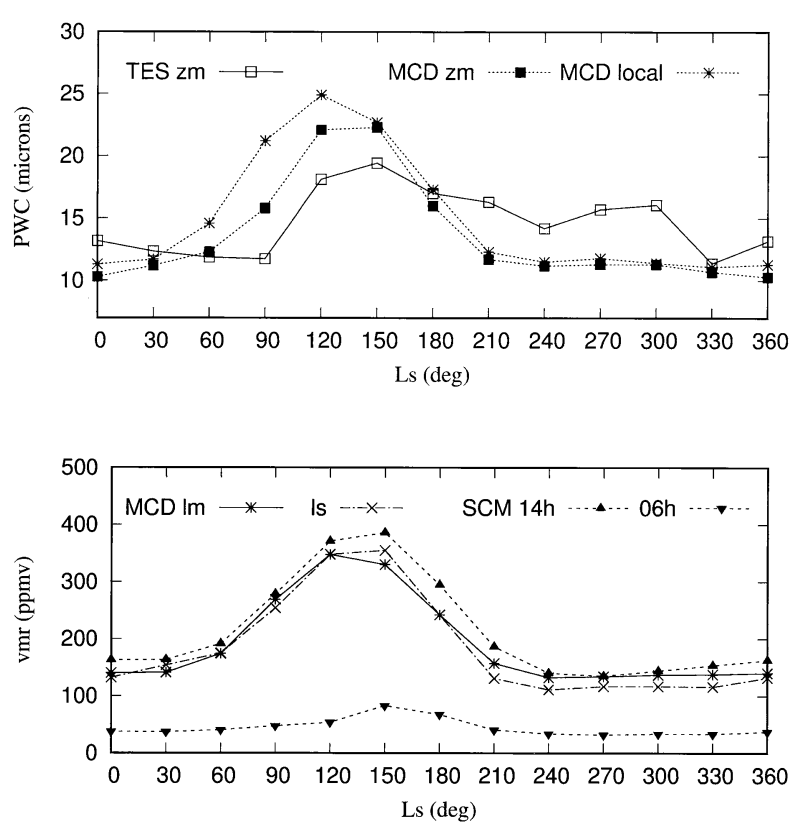

Fig. 11 The local mean vmr from $M C D 12 \mathrm{~h}$ PWC at Jezero $(M C D \mathrm{~lm})$, the respective local surface value of the vmr (ls), and $14 \mathrm{~h}$ and $06 \mathrm{~h}$ vmr at $1.6 \mathrm{~m}$ from $S C M$, model having been initialized using the local MCD 12 h PWC

air from the midlatitudes. Moister air hence lies aloft (e.g. Montmessin et al. 2017). As a result, the midday surface water vapor volume mixing ratio (hereafter vmr) at Jezero might be close to the mean vmr obtained from the respective PWC by assuming vertically evenly mixed moisture. Figure 11 displays this local mean vmr ( $\mathrm{lm}$, solid line) together with the actual local surface-vmr (ls, dash-dot line) from the MCD $12 \mathrm{~h}$ Jezero moisture profiles. The two are indeed quite close to each other during all seasons. Hence we may initialize the column model's water vapor mixing ratios in the air and within the soil pores at Jezero by using the mean vmr from the input-PWC and $\mathrm{p}$ from Table 5, the initial near-surface air and in-pore vapor mixing ratios then being realistic during all seasons according to Fig. 11.

Figure 11 also displays, for comparison, the $S C M$-produced main results: the daily afternoon maxima $(14 \mathrm{~h})$ and near-sunrise minima $(06 \mathrm{~h})$ of the vmr at $1.6 \mathrm{~m}$. SCM is here initialized for each Ls using the local $M C D$ PWC at Jezero from Table 5. The predicted pre-dawn minima of the vmr are quite low throughout the year, 40-80 ppmv, due to the nocturnal water adsorption onto porous regolith as in Fig. 9. Adsorption begins in the model at about $1700 \mathrm{LT}$ and depletes moisture from the lowest $200 \mathrm{~m}$ of air during the night. After sunrise the ground warms up and the water molecules are desorbed back to the air, hence increasing the afternoon maxima of the vmr at $1.6 \mathrm{~m}$ slightly above the values of the vertically averaged mean vmr. The daily "breathing" of the regolith goes on throughout the martian year [Beck et al. 2010].

Figure 12 shows the model's daily min and max vmr at $1.6 \mathrm{~m}$, when initialized by the local MCD PWC (from Fig. 11), together with the daily min and max vmr when the model is initialized instead by using the observed TES MY26 zonal mean PWC. The pre-dawn minima of the vmr are not very sensitive to the prevailing PWC, hovering around 30-90 ppmv throughout the martian year. The afternoon maxima of the vmr vary more, from less than 200 ppmv most of the time, to $250-400$ ppmv during the moist season at the Jezero latitude, Ls $120^{\circ}-180^{\circ}$. These predicted daily extremes of the vmr for Jezero are smaller than during the quite moist polar midsummer at Phoenix (Fig. 9). 
Table 6 SCM results: Predicted air temperatures T $(\mathrm{K})$ and water vapor volume mixing ratios vmr (ppmv) for $0600 \mathrm{LT}$ and $1400 \mathrm{LT}$, and relative humidities RH (\%) for $0600 \mathrm{LT}$, all at $1.6 \mathrm{~m}$ height at the Jezero site $\left(18.4^{\circ} \mathrm{N}, 77.6^{\circ} \mathrm{E}\right)$. Model inputs are from Table 5. The predicted $1400 \mathrm{LT}$ RH (not shown) is well below $1 \%$ during all seasons

\begin{tabular}{lllllll}
\hline $\mathrm{L}_{\mathrm{S}}$ & $0^{\circ}$ & $30^{\circ}$ & $60^{\circ}$ & $90^{\circ}$ & $120^{\circ}$ & $150^{\circ}$ \\
\hline $0600 \mathrm{LT}$ & & & & & & \\
T, K & 193 & 193 & 191 & 190 & 190 & 193 \\
vmr, ppmv & $37-40$ & $36-37$ & $33-41$ & $36-48$ & $51-54$ & $71-83$ \\
RH, \% & $49-56$ & $51-53$ & $63-77$ & $89-108$ & $103-107$ & $83-96$ \\
1400 LT & & & & & & \\
T, K & 252 & 251 & 245 & 240 & 244 & 255 \\
vmr, ppmv & $163-189$ & $164-172$ & $156-191$ & $155-279$ & $274-371$ & $332-371$ \\
Ls & $180^{\circ}$ & $210^{\circ}$ & $240^{\circ}$ & $270^{\circ}$ & $300^{\circ}$ & $330^{\circ}$ \\
0600 LT & & & & & & \\
T, K & 195 & 194 & 193 & 191 & 191 & 192 \\
vmr, ppmv & $67-68$ & $41-54$ & $34-40$ & $32-41$ & $34-45$ & $33-34$ \\
RH, \% & $59-60$ & $44-51$ & $50-62$ & $70-91$ & $69-95$ & $52-54$ \\
1400 LT & & & & & & \\
T, K & 261 & 256 & 246 & 241 & 244 & 249 \\
vmr, ppmv & $290-295$ & $186-245$ & $140-173$ & $135-180$ & $144-203$ & $154-158$ \\
\hline
\end{tabular}

Fig. 12 The daily max $(14 \mathrm{~h})$ and $\min (06 \mathrm{~h}) \mathrm{vmr}$ at $1.6 \mathrm{~m}$ for Jezero from $S C M$, initialized either via the $M C D$ local PWC or via the TES MY26 zonal mean PWC for the Jezero latitude of $18^{\circ} \mathrm{N}$

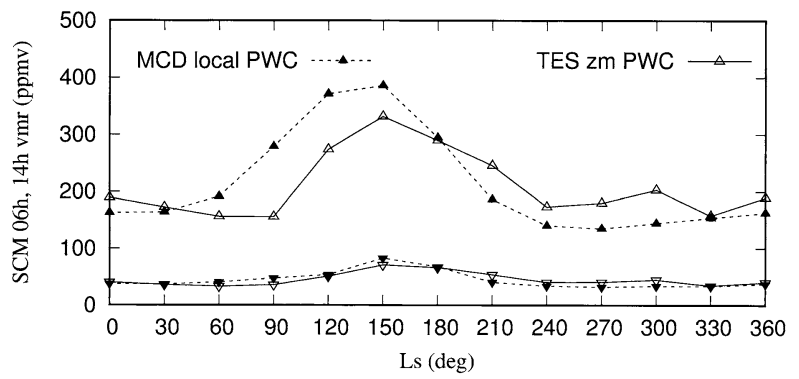

Table 6 provides numerical values for the $S C M$-predicted diurnal ranges of expected air temperatures, $\mathrm{RH}$ and vmr at $1.6 \mathrm{~m}$ height at the Jezero site, assuming normal dustiness and regolith-covered martian topsoil. The ranges are based on the two extreme PWC scenarios of Fig. 10. Small variations in the other model input values have much less impact on the nearsurface moisture. Evening adsorption removes moisture from the air so effectively that night fogs and frosts do not develop in the SCM experiments with adsorption, although in reality thin fogs might occasionally appear during Ls $90^{\circ}-120^{\circ}$, when the predicted nighttime $\mathrm{RH}$ at $1.6 \mathrm{~m}$ exceeds $100 \%$ in Table 6 .

Should the ground at Jezero crater be instead dominated by exposed bedrock with little porosity, there is much less adsorption. Consequently, nocturnal frosts and fogs would then be relatively common at such regions during all seasons according to the simulations. 


\section{Summary and Conclusions}

The output from various models were compared and contrasted in order to provide predictions for what the MEDA weather instrument investigation on Mars 2020 Perseverance rover will encounter. Generally, there is a good agreement between MRAMS and MarsWRF models, and where there is disagreement it certainly motivates in situ measurements of the nearsurface atmosphere, both to identify which model(s) perform best for predicting each aspect of the meteorology at a given landing site, and more importantly to understand why this is. The latter investigation enables us to identify strengths and weaknesses of physics schemes, dust prescriptions, diffusion parameters, dynamical cores, etc. The predicted diurnal variations of the pressure cycle were shown to be largely similar for MRAMS and MarsWRF. The total amplitude of pressure at Jezero crater is substantially smaller compared to Gale crater, so the crater circulation at Jezero crater does not appear to significantly amplify the amplitude of the diurnal pressure. Some differences in the phasing of waves were noted in the pressure curves. The general shape of the diurnal cycle of surface temperature signal were similar between the MRAMS and MarsWRF, but this is expected given that they are strongly controlled by the time variation of solar insolation. There are some differences in the details. The warmer temperatures in MRAMS, more so during daytime, compared with MarsWRF during all seasons could be suggestive of a combination of differences between models such an different values of surface properties and column dust opacity (Tables 1 and 2), different radiation and subsurface schemes used, different parameterized turbulence and heat fluxes used, and/or different vertical dust prescriptions. Both models show high frequency turbulent variations in air temperature during the afternoon and occasional nocturnal turbulence that must be driven by increasingly strong shear (onset of the nocturnal low-level jet) at the nocturnal inversion interface. The strongest modeled winds occur in the mid-afternoon (when upslope winds are strongest) peaking at $\sim 16 \mathrm{~m} / \mathrm{s}$ at $\mathrm{L}_{\mathrm{s}} 0^{\circ}$ and $\mathrm{L}_{\mathrm{s}} 180^{\circ}$. At all seasons, modeled winds are from the $\sim \mathrm{NW}$ at night and then transition to a $\sim$ SE direction during the day (Fig. 6), consistent with the diurnal slope winds in the Isidis Basin, as described in [N20]. The highest solar fluxes (for the periods considered) are found at $\mathrm{L}_{\mathrm{s}} 180^{\circ}$ (Fig. 8), in agreement with the highest air and surface temperatures (Figs. 3 and 4). The most humid season is $\mathrm{L}_{\mathrm{s}} \sim 120-180^{\circ}$, peaking at $\mathrm{L}_{\mathrm{s}} \sim 150^{\circ}$, with implications for atmosphere-regolith interactions and astrobiology. Thin fogs might occasionally appear during $\mathrm{L}_{\mathrm{s}} \sim 90^{\circ}-120^{\circ}$, when the predicted nighttime relative humidity at $1.6 \mathrm{~m}$ exceeds $100 \%$.

The meteorological predictions parameters in this manuscript will be used for comparison to observations after Mars2020 Perseverance rover lands. A more comprehensive analysis of the regional and large scale atmospheric circulation that affects Jezero crater is given in [N20].

Acknowledgements This research has been partially supported by the Spanish Ministry of Economy and Competiveness (MINECO), under project ESP2016-79612-C3-1-R. S.R. supported this work on his own time in the absence of funding. Germán Martinez wishes to acknowledge USRA contract number 1638782. MTJ's work was carried out at the Jet Propulsion Laboratory/California Institute of Technology. MTJ and CEN acknowledge support from NASA's STMD and GCD directorates through the M2020 project. A.M. is funded by the Project "MarsFirstWater", European Research Council, Consolidator Grant no. 818602. In addition, we wish to express our gratitude to the MEDA instrument team members to supporting this investigation. Authors also thank the Agencia Estatal de Investigación (AEI) project no. MDM-2017-0737 Unidad de Excelencia "María de Maeztu" Centro de Astrobiología (CSIC-INTA).

Supplementary Material The atmospheric circulation animations associated with this article, including winds and potential temperature for all the solstices and equinoxes of Jezero crater region, can be found, in the online version, at: https://data.boulder.swri.edu/jpla/2020paper/animations/.

In the animations, the $x-y$ axis labels distance in $\mathrm{km}$, and the Mars 2020 Perseverance rover landing site location inside Jezero crater $\left[77.4298^{\circ} \mathrm{E}, 18.4663{ }^{\circ} \mathrm{N}\right]$ corresponds to $x=55$ and $y=66$. 
Publisher's Note Springer Nature remains neutral with regard to jurisdictional claims in published maps and institutional affiliations.

Open Access This article is licensed under a Creative Commons Attribution 4.0 International License, which permits use, sharing, adaptation, distribution and reproduction in any medium or format, as long as you give appropriate credit to the original author(s) and the source, provide a link to the Creative Commons licence, and indicate if changes were made. The images or other third party material in this article are included in the article's Creative Commons licence, unless indicated otherwise in a credit line to the material. If material is not included in the article's Creative Commons licence and your intended use is not permitted by statutory regulation or exceeds the permitted use, you will need to obtain permission directly from the copyright holder. To view a copy of this licence, visit http://creativecommons.org/licenses/by/4.0/.

\section{References}

F. Ayoub, J.P. Avouac, C.E. Newman, M.I. Richardson, A. Lucas, S. Leprince, N.T. Bridges, Threshold for sand mobility on Mars calibrated from seasonal variations of sand flux. Nat. Commun. 5(1), 1-8 (2014)

D. Banfield, A. Spiga, C. Newman, F. Forget, M. Lemmon, R. Lorenz et al., The atmosphere of Mars as observed by InSight. Nat. Geosci. 13, 190-198 (2020)

P. Beck, A. Pommerol, B. Schmitt, O. Brissaud, Kinetics of water adsorption on minerals and the breathing of the Martian regolith. J. Geophys. Res., Planets 115(E10), E10011 (2010)

T. Bertrand, A. Spiga, S. Rafkin, A. Colaitis, F. Forget, E. Millour, LMD SWRI martian mesoscale and microscale model intercomparison for ExoMars landing characterization. MAMO 1319, (2014)

A.K. Blackadar, Boundary layer wind maxima and their significance for the growth of nocturnal inversions. Bull. Am. Meteorol. Soc. 38(5), 283-290 (1957)

A.J. Brown, Spectral bluing induced by small particles under the Mie and Rayleigh regimes. Icarus 239 , 85-95 (2014)

A.J. Brown, C.E. Viviano, T.A. Goudge, Olivine-carbonate mineralogy of the Jezero Crater region. J. Geophys. Res., Planets 125(3), e2019JE006011 (2020)

R.T. Clancy, S.W. Lee, G.R. Gladstone, W.W. McMillan, T. Rousch, A new model for Mars atmospheric dust based upon analysis of ultraviolet through infrared observations from Mariner 9, Viking, and Phobos. J. Geophys. Res., Planets 100(E3), 5251-5263 (1995)

B.J. Conrath, Thermal structure of the Martian atmosphere during the dissipation of the dust storm of 1971. Icarus 24(1), 36-46 (1975)

P.A. Davis, Development and mechanisms of the nocturnal jet. Meteorol. Appl. 7(3), 239-246 (2000)

A.K. Farley et al., Mars 2020 Mission Overview. Space Sci. Rev. (2020). https://doi.org/10.1007/s11214020-00762-y

C.I. Fassett, J.W. Head III, Fluvial sedimentary deposits on Mars: ancient deltas in a crater lake in the Nili Fossae region. Geophys. Res. Lett. 32(14), L14201 (2005)

E. Fischer, G.M. Martínez, N.O. Rennó, L.K. Tamppari, A.P. Zent, Relative humidity on Mars: new results from the Phoenix TECP sensor. J. Geophys. Res., Planets (2019, accepted)

J. Gómez-Elvira, C. Armiens, I. Carrasco, M. Genzer, F. Gómez, R. Haberle et al., Curiosity’s rover environmental monitoring station: Overview of the first 100 sols. J. Geophys. Res., Planets 119(7), 1680-1688 (2014)

T.A. Goudge, J.F. Mustard, J.W. Head, C.I. Fassett, S.M. Wiseman, Assessing the mineralogy of the watershed and fan deposits of the Jezero crater paleolake system, Mars. J. Geophys. Res., Planets 120(4), 775-808 (2015)

S.D. Guzewich, E.R. Talaat, A.D. Toigo, D.W. Waugh, T.H. McConnochie, High-altitude dust layers on Mars: observations with the Thermal Emission Spectrometer. J. Geophys. Res., Planets 118(6), 1177-1194 (2013)

B.H. Horgan, R.B. Anderson, G. Dromart, E.S. Amador, M.S. Rice, The mineral diversity of Jezero crater: evidence for possible lacustrine carbonates on Mars. Icarus 339, 113526 (2020)

J.H. Joseph, W.J. Wiscombe, J.A. Weinman, The delta-Eddington approximation for radiative flux transfer. J. Atmos. Sci. 33(12), 2452-2459 (1976). https://doi.org/10.1175/1520-0469(1976)033 $<2452$ :TDEAFR $>2.0 . \mathrm{CO} ; 2$

M.A. Kahre, J.R. Murphy, R.M. Haberle, Modelling the Martian dust cycle and surface dust reservoirs with the NASA Ames general circulation model. J. Geophys. Res., Planets 111(6), E06008 (2006)

H.H. Kieffer, Thermal model for analysis of Mars infrared mapping. J. Geophys. Res., Planets 118(3), 451470 (2013) 
C. Lee, M.I. Richardson, C.E. Newman, M.A. Mischna, The sensitivity of solsticial pauses to atmospheric ice and dust in the MarsWRF General Circulation Model. Icarus 311, 23-34 (2018)

M.T. Lemmon, M.J. Wolff, J.F. Bell III, M.D. Smith, B.A. Cantor, P.H. Smith, Dust aerosol, clouds, and the atmospheric optical depth record over 5 Mars years of the Mars Exploration Rover mission. Icarus 251, 96-111 (2015)

L. Mahrt, The early evening boundary layer transition. Q. J. R. Meteorol. Soc. 107(452), 329-343 (1981)

L. Mandon, C. Quantin-Nataf, P. Thollot, N. Mangold, L. Lozac'h, G. Dromart et al., Refining the age, emplacement and alteration scenarios of the olivine-rich unit in the Nili Fossae region, Mars. Icarus 336, 113436 (2020)

G.M. Martínez, C.N. Newman, A. De Vicente-Retortillo, E. Fischer, N.O. Renno, M.I. Richardson et al., The modern near-surface Martian climate: a review of in-situ meteorological data from Viking to Curiosity. Space Sci. Rev. 212(1-2), 295-338 (2017)

G. Mellor, T. Yamada, A hierarchy of turbulence closure models for planetary boundary layers. J. Atmos. Sci. 31, 1791-1806 (1974)

J.W. Miles, On the stability of heterogeneous shear flows. J. Fluid Mech. 10(4), 496-508 (1961)

E. Millour et al., The Mars Climate Database (version 5.3), in Scientific Workshop: "From Mars Express to ExoMars", ESAC Madrid, Spain (2018)

M.A. Mischna, C. Lee, M. Richardson, Development of a fast, accurate radiative transfer model for the Martian atmosphere, past and present. J. Geophys. Res., Planets 117(E10), E10009 (2012)

M.I. Mishchenko, L.D. Travis, Capabilities and limitations of a current FORTRAN implementation of the T-matrix method for randomly oriented, rotationally symmetric scatterers. J. Quant. Spectrosc. Radiat. Transf. 60(3), 309-324 (1998)

F. Montmessin, M.D. Smith, Y. Langevin, M.T. Mellon, A. Fedorova, The water cycle, in The Atmosphere and Climate of Mars, ed. by R.M. Haberle, R. Todd Clancy, F. Forget, M.D. Smith, R.W. Zurek (Cambridge University Press, Cambridge, 2017), pp. 338-373. 644 pp.

T. Navarro et al., Global climate modeling of the Martian water cycle with improved microphysics and radiatively active water ice clouds. J. Geophys. Res., Planets 119, 1479-1495 (2014)

C.E. Newman, J. Gómez-Elvira, M. Marin, S. Navarro, J. Torres, M.I. Richardson, J.M. Battalio, S.D. Guzewich, R. Sullivan, M. de la Torre, A.R. Vasavada, N.T. Bridges, Winds measured by the Rover Environmental Monitoring Station (REMS) during the Mars Science Laboratory (MSL) rover's Bagnold Dunes Campaign and comparison with numerical modeling using MarsWRF. Icarus 291, 203-231 (2017). https://doi.org/10.1016/j.icarus.2016.12.016

C.E. Newman, H. Kahanpää, M.I. Richardson, G. Martínez, Á. Vicente-Retortillo, M.T. Lemmon, Convective vortex and dust devil predictions for Gale Crater over 3 Mars years and comparison with MSL-REMS observations. Published online in JGR-Planets (2019)

C.E. Newman, et al., Multi-model meteorological and aeolian predictions for Mars2020 and the Jezero crater region. Space Sci. Rev. (2020, this issue)

J. Pla-Garcia, S.C.R. Rafkin, M. Kahre, J. Gomez-Elvira, V.E. Hamilton, S. Navarro, J. Torres, M. Marín, A.R. Vasavada, The meteorology of Gale crater as determined from rover environmental monitoring station observations and numerical modeling. Part I: comparison of model simulations with observations. Icarus 280, 103-113 (2016). https://doi.org/10.1016/j.icarus.2016.03.013

J.G. Powers, J.B. Klemp, W.C. Skamarock, C.A. Davis, J. Dudhia, D.O. Gill et al., The weather research and forecasting model: overview, system efforts, and future directions. Bull. Am. Meteorol. Soc. 98(8), 1717-1737 (2017)

S.C.R. Rafkin, A positive radiative-dynamic feedback mechanism for the maintenance and growth of Martian dust storms. J. Geophys. Res. 114, E01009 (2009)

S. Rafkin, T. Michaels, The Mars Regional Atmospheric Modeling System (MRAMS): current status and future directions. Atmosphere 10(12), 747 (2019)

S.C.R. Rafkin, R.M. Haberle, T.I. Michaels, The Mars Regional Atmospheric Modeling System (MRAMS): model description and selected simulations. Icarus 151, 228-256 (2001)

S.C.R. Rafkin, M.R.V. Sta Maria, T.I. Michaels, Simulation of the atmospheric thermal circulation of a martian volcano using a mesoscale numerical model. Nature 419, 697-699 (2002)

S.C.R. Rafkin et al., The meteorology of Gale Crater as determined from Rover Environmental Monitoring Station observations and numerical modeling. Part II: interpretation. Icarus 280, 114-138 (2016)

M.I. Richardson, C.E. Newman, On the relationship between surface pressure, terrain elevation, and air temperature. Part I: the large diurnal surface pressure range at Gale Crater, Mars and its origin due to lateral hydrostatic adjustment. Planet. Space Sci. 164, 132-157 (2018)

M.I. Richardson, A.D. Toigo, C.E. Newman, PlanetWRF: a general purpose, local to global numerical model for planetary atmospheric and climate dynamics. J. Geophys. Res., Planets 112(E9), E09001 (2007)

J.A. Rodriguez-Manfredi, et al., The Mars Environmental Dynamics Analyzer, MEDA. A suite of environmental sensors for the Mars 2020 mission. Space Sci. Rev. (2020, this issue) 
H. Savijärvi, A. Määttänen, Boundary-layer simulations for the Mars Phoenix lander site. Q. J. R. Meteorol. Soc. 136, 1497-1505 (2010). https://doi.org/10.1002/qj.650

H. Savijärvi, A-M. Harri, O. Kemppinen, The diurnal water cycle at Curiosity: role of exchange with the regolith. Icarus 265, 63-69 (2016). https://doi.org/10.1016/j.icarus.2015.10.008

H. Savijärvi, M. Paton, A.-M. Harri, New column simulations for the Viking landers: winds, fog, frost, adsorption? Icarus 310, 48-53 (2017). https://doi.org/10.1016/j.icarus.2017.11.007

H. Savijärvi, G.M. Martinez, E. Fischer, N. Renno, L. Tamppari, A. Zent, A.-M. Harri, Humidity observations and column simulations for a warm period at the Mars Phoenix lander site: constraining the adsorptive properties of regolith. Icarus (2020)

J.T. Schofield, J.R. Barnes, D. Crisp, R.M. Haberle, S. Larsen, J.A. Magalhães, J.R. Murphy, A. Seiff, G. Wilson, The Mars Pathfinder Atmospheric Structure Investigation/Meteorology (ASI/MET) experiment. Science 278(5344), 1752-1758 (1997)

S.C. Schon, J.W. Head, C.I. Fassett, An overfilled lacustrine system and progradational delta in Jezero crater, Mars: implications for Noachian climate. Planet. Space Sci. 67(1), 28-45 (2012)

W.C. Skamarock, J.B. Klemp, J. Dudhia, D.O. Gill, D.M. Barker, W. Wang, J.G. Powers, A description of the Advanced Research WRF version 3. NCAR Technical note-475+ STR (2008)

M.D. Smith, J.C. Pearl, B.J. Conrath, P.R. Christensen, Mars Global Surveyor Thermal Emission Spectrometer (TES) observations of dust opacity during aerobraking and science phasing. J. Geophys. Res., Planets 105(E4), 9539-9552 (2000)

K. Stamnes, S.C. Tsay, W. Wiscombe, K. Jayaweera, Numerically stable algorithm for discrete-ordinatemethod radiative transfer in multiple scattering and emitting layered media. Appl. Opt. 27, 2502-2509 (1988). https://doi.org/10.1364/AO.27.002502

L.J. Steele, M.R. Balme, S.R. Lewis, A. Spiga, The water cycle and regolith-atmosphere interaction at Gale crater, Mars. Icarus 280, 56-79 (2017)

A.J. Thorpe, T.H. Guymer, The nocturnal jet. Q. J. R. Meteorol. Soc. 103(438), 633-653 (1977)

A.D. Toigo, C. Lee, C.E. Newman, M.I. Richardson, The impact of resolution on the dynamics of the martian global atmosphere: varying resolution studies with the MarsWRF GCM. Icarus 221(1), 276-288 (2012)

D. Tyler Jr., J.R. Barnes, Mesoscale modeling of the circulation in the Gale Crater region: an investigation into the complex forcing of convective boundary layer depths. Mars Int. J. Mars Sci. Explor. 8, 58-77 (2013)

A. Vasavada, A. Chen, J. Barnes, P.D. Burkhart, B. Cantor, A. Dwyer-Cianciolo, R. Fergason, D. Hinson, H. Justh, D. Kass, S. Lewis, M. Mischna, J. Murphy, S.R. Rafkin, D. Tyler, P. Withers, Assessment of environments for Mars science laboratory entry, descent, and surface operations. Space Sci. Rev. 170(1-4), 793-835 (2012)

A. Vicente-Retortillo, F. Valero, L. Vázquez, G.M. Martínez, A model to calculate solar radiation fluxes on the Martian surface. J. Space Weather Space Clim. 5, A33 (2015). https://doi.org/10.1051/swsc/2015035

Á. Vicente-Retortillo, G.M. Martínez, N. Renno, C.E. Newman, I. Ordonez-Etxeberria, M.T. Lemmon et al., Seasonal deposition and lifting of dust on Mars as observed by the Curiosity rover. Sci. Rep. 8(1), 1-8 (2018)

D. Viúdez-Moreiras, J. Gómez-Elvira, C.E. Newman, S. Navarro, M. Marin, J. Torres, M. de la TorreJuárez (the REMS team), Gale surface wind characterization based on the Mars Science Laboratory REMS dataset. Part I: wind speeds and directions. Icarus 319, 909-925 (2019a). https://doi.org/10.1016/ j.icarus.2018.10.011

D. Viúdez-Moreiras, J. Gómez-Elvira, C.E. Newman, S. Navarro, M. Marin, J. Torres, M. de la Torre-Juárez (the REMS team), Gale surface wind characterization based on the Mars Science Laboratory REMS dataset. Part II: wind probability distributions. Icarus 319, 645-656 (2019b). https://doi.org/10.1016/ j.icarus.2018.10.010

K.H. Williford, K.A. Farley, K.M. Stack, A.C. Allwood, D. Beaty, L.W. Beegle et al., The NASA Mars 2020 rover mission and the search for extraterrestrial life, in From Habitability to Life on Mars (Elsevier, Amsterdam, 2018), pp. 275-308

M.J. Wolff, M.D. Smith, R.T. Clancy, R. Arvidson, M. Kahre, F. Seelos IV, S. Murchie, H. Savijärvi, Wavelength dependence of dust aerosol single-scattering albedo as observed by the Compact Reconnaissance Imaging Spectrometer. J. Geophys. Res. 114, E00D04 (2009). https://doi.org/10.1029/2009JE003350

M.J. Wolff, R.T. Clancy, J.D. Goguen, M.C. Malin, B.A. Cantor, Ultraviolet dust aerosol properties as observed by MARCI. Icarus 208, 143-155 (2010). https://doi.org/10.1016/j.icarus.2010.01.010

J.C. Wyngaard, Toward numerical modeling in the "Terra Incognita". J. Atmos. Sci. 61(14), 1816-1826 (2004) 